\title{
Mapping quantitative trait loci for resistance to Pratylenchus thornei from synthetic hexaploid wheat in the International Triticeae Mapping Initiative (ITMI) population
}

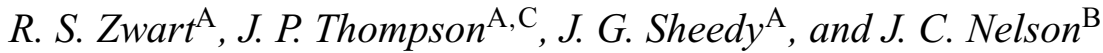

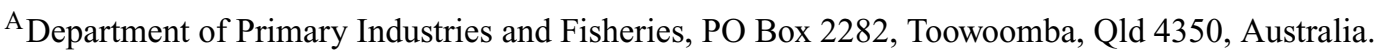 \\ ${ }^{B}$ Department of Plant Pathology, 4024 Throckmorton Hall, Kansas State University, Manhattan, KS, USA. \\ ${ }^{\mathrm{C}}$ Corresponding author. Email: john.thompson@dpi.qld.gov.au
}

\begin{abstract}
Root-lesion nematode (Pratylenchus thornei) is a serious pathogen of wheat in many countries. The International Triticeae Mapping Initiative (ITMI) population of recombinant inbred lines (RILs) was assessed for resistance to $P$. thornei to determine the chromosome locations of the resistance genes. The ITMI population is derived from a cross between the resistant synthetic hexaploid wheat W-7984 and a susceptible bread wheat cultivar Opata 85. Two years of phenotypic data for resistance to $P$. thornei were obtained in replicated glasshouse trials. Quantitative trait locus (QTL) analysis was performed using available segregation and map data for 114 RILs. A QTL on chromosome 6DS showed consistent effects for reduced nematode numbers (partial resistance) across years and accounted for $11 \%$ and $23 \%$ of the phenotypic variation. A second QTL for P. thornei resistance on chromosome 2BS accounted for an additional 19\% and 5\%. Restriction fragment length polymorphism (RFLP) and simple sequence repeat (SSR) markers associated with the QTLs are physically located in regions rich in major genes at the distal ends of the short chromosome arms of 6D and 2B. SSR markers with potential for marker-assisted selection of $P$. thornei resistance effective in different genetic backgrounds have been identified.
\end{abstract}

Additional keywords: root-lesion nematodes, bread wheat, molecular markers, MAS, composite interval mapping, QTL Cartographer, W-7984, Opata 85.

\section{Introduction}

Root-lesion nematode (Pratylenchus thornei Sher and Allen) causes serious yield reduction in Australian wheat (Triticum aestivum L.) with average losses estimated at \$AU36 M annually (Brennan and Murray 1998). P. thornei is a migratory, vermiform nematode about $0.7 \mathrm{~mm}$ long that penetrates the root cortex, where it feeds, reproduces, and disrupts root function (Loof 1991). The nematode passes through its lifecycle in about 6 weeks under favourable conditions. High populations of P. thornei (>2000/kg soil) present at sowing can severely affect plants, which may show symptoms of nutrient deficiencies and water stress.

Pratylenchus thornei can occur in large numbers throughout the soil profile, which makes nematicide application uneconomical at the rates necessary for effective control (Thompson et al. 1982; Vanstone et al. 1998). Currently, the best control strategy is an integrated approach that combines the use of tolerant and resistant crop varieties, crop rotation, and farm hygiene. Although commercial wheat varieties with superior tolerance to $P$. thornei are available, these varieties still allow nematodes to multiply in their roots and leave a residual nematode population in the soil to attack subsequent crops (Thompson et al. 1999). So the key component of this strategy to manage nematodes is the use of resistant varieties that prevent nematode reproduction.

Current Australian wheat varieties have poor levels of resistance to $P$. thornei and backcrossing is being pursued to incorporate resistance into commercial varieties. GS50a, a selection from the Australian bread wheat variety Gatcher, is the most widely used source of $P$. thornei resistance (Thompson et al. 1999). Extensive screening for new sources of resistance to $P$. thornei has identified several landrace wheats, namely AUS4930 (Iraq 48) (Nicol et al. 1998) and AUS13124 (Morocco 426) and AUS4926 (Iraq 43) (Seymour and Thompson 2001) with resistance levels equivalent to or better than that of GS50a (Zwart et al. 2004b). Other sources of resistance to $P$. thornei have been found in the wild grass Aegilops tauschii Coss. $(2 \mathrm{n}=14$, DD) (Thompson and Haak 1997), in durum wheats Triticum turgidum L. subsp. durum (Desf.) Husn $(2 \mathrm{n}=28$, AABB) (J. P. Thompson and M. I. Haak, unpublished data), and in synthetic hexaploid wheats produced from their hybridisation ( $T$. aestivum, $2 \mathrm{n}=42$, AABBDD) (Zwart et al. 2004a). 
Recent molecular marker studies have identified putative quantitative trait loci (QTLs) for resistance to P. thornei on chromosomes 2B (Schmidt et al. 2005; Zwart et al. 2005), 3B (Schmidt et al. 2005), and 6A and 6D (Zwart et al. 2005), and a QTL for susceptibility to P. thornei on 1B (Schmidt et al. 2005). These mapping studies were conducted using framework maps with a minimum number of marker loci used to detect marker-trait associations. The numbers of marker loci and genome coverage of these maps were 114 markers over $1987 \mathrm{cM}$ for AUS1312 $\times$ Janz, 148 markers over $3230 \mathrm{cM}$ for AUS4926 $\times$ Janz (Schmidt et al. 2005), and 169 markers over $2570 \mathrm{cM}$ for CPI $133872 \times$ Janz (Zwart et al. 2005).

In comparison, the International Triticeae Mapping Initiative (ITMI) population (W-7984 $\times$ Opata 85$)$, the most densely mapped wheat population available internationally, has 1406 marker loci and a total genome coverage of $2654 \mathrm{cM}$ (Song et al. 2005). A considerable number of marker loci on the ITMI genetic linkage map have been physically mapped into deletion bins (Erayman et al. 2004; Sourdille et al. 2004). The high marker density and extensive genome coverage of both the genetic linkage and physical consensus maps, in addition to the segregation of the recombinant inbred lines (RILs) for resistance to $P$. thornei and molecular marker data being publicly available from GrainGenes, make this population an ideal resource for the identification of QTLs associated with $P$. thornei resistance.

The objective of this study was to utilise the available information on genetic linkage and physical maps of wheat in order to locate QTLs associated with resistance to $P$. thornei in the ITMI population.

\section{Materials and methods}

\section{Mapping population}

The ITMI population consists of a total of 150 RILs derived by singleseed descent from the cross of the synthetic hexaploid wheat W-7984 (also designated M6, P. McGuire, pers. comm.) and the hard red spring wheat cultivar Opata 85 (Nelson et al. 1995a). The synthetic hexaploid wheat was originally reported as produced from the hybridisation of durum wheat cultivar Altar 84 and Aegilops tauschii accession CI 18 (Nelson et al. 1995a). This synthetic wheat is the same as CIMMYT Synthetic ID No. 48 and CIGM86.940 in appendix 2 of Mujeeb-Kazi (1995) in which the pedigree is given as durum Altar 84 crossed with Ae. tauschii (CIMMYT WX 219, syn. TA2465). However, there is uncertainty that Altar 84 is the durum component of the synthetic hexaploid (Singh et al. 2000). Seeds of the $\mathrm{F}_{7}$ generation of RILs were kindly provided by Dr P. J. Sharp, University of Sydney, Australia, for phenotypic assessment of $P$. thornei resistance in 1997. The RILs were later reselected to eliminate morpho-variants and advanced to the $\mathrm{F}_{11}$ generation at Cornell University, USA. Seeds of the reselected ITMI population were provided by Dr K. J. Chalmers, University of Adelaide, Australia, for phenotypic assessment of $P$. thornei resistance in 2001 .

\section{Phenotypic assessment of $\mathrm{P}$. thornei resistance}

Resistance to $P$. thornei was assessed in the glasshouse using randomised block design experiments, repeated twice. In the first experiment, conducted in 1997, 3 replicates of a subset of 91 RILs were assessed for resistance to $P$. thornei using the procedure described by Thompson et al. (1999). In the second experiment, conducted in 2001, 4 replicates of 129 RILs were assessed for $P$. thornei resistance based on nematode counts in soil and roots as described by Zwart et al. (2004a). Count data were transformed by $\ln (x+c)$, where $x$ is nematodes $/ \mathrm{kg}$ soil and roots sampled, and $c$ is constant. The value of $c$ was optimised for each experiment using chi-squared principles to normalise the data (Proctor and Marks 1974; Berry 1987). Analysis of variance was performed using Genstat 6.1 (Payne et al. 2002) and mean squares were used to estimate heritability of $P$. thornei resistance in the ITMI population (Hartl et al. 1988).

\section{Linkage map}

The marker segregation data for 114 RILs was obtained from the GrainGenes database (http://wheat.pw.usda.gov). QTL analysis was performed on a subset of 537 restriction fragment length polymorphism (RFLP) markers (Van Deynze et al. 1995; Nelson et al. 1995a, 1995b, 1995c; Marino et al. 1996) and simple sequence repeat (SSR) markers (gwm, Röder et al. 1998; and barc, Song et al. 2005). The marker order in the QTL regions, initially based on the consensus map of Somers et al. (2004), was adjusted with Mapmaker software (Lander et al. 1987). The genetic linkage map was compared with the consensus wheat physical maps (Erayman et al. 2004; Sourdille et al. 2004; Shah and Hassan 2005) to reveal the physical locations of the QTLs for P. thornei resistance.

\section{QTL analysis}

QTL analysis was performed on RIL means from the ANOVA of transformed nematode counts for each year, as well as on the individual replicate data. The locations and effects of QTLs were determined by composite interval mapping using the computer program QTL Cartographer v2.5 (Wang et al. 2005). The threshold LOD score for detection of QTL at $P=0.05$ was calculated for each set of phenotypic data using 1000 permutations (Churchill and Doerge 1994). The proportion of observed phenotypic variation explained due to a particular QTL was estimated by the coefficient of determination $\left(R^{2}\right)$. Composite interval mapping was performed using forward stepwise regression with a window size of $10 \mathrm{cM}$ and background control set at 5 markers.

\section{Results}

Phenotypic assessment of $\mathrm{P}$. thornei resistance

The 2 parents of the ITMI population differed significantly in resistance to $P$. thornei (Table 1), with the synthetic hexaploid parent, W-7984, resistant and the bread wheat parent, Opata 85, susceptible. W-7984 showed a resistance level equivalent to (1997) or better than (2001) the resistance level of GS50a, the current standard for $P$. thornei resistance. The RILs population segregated in a continuous distribution for resistance to P. thornei (Fig. 1). Mean nematode counts of the RILs ranged from 4850 to $120556 P$. thornei $/ \mathrm{kg}$ soil and roots in 1997 and 4592 to 367962 in 2001 . The heritability estimates for P. thornei resistance were 0.83 and 0.84 in 1997 and 2001 , respectively. There was significant correlation between nematode counts in the 2 years of phenotyping $(r=0.37$, d.f. $=86, P<0.001)$. In 1997, 52 RILs showed a resistance level higher than or equivalent to the resistant parent, W7984. In 2001, 35 RILs showed a resistance level higher 
Table 1. The parents, W-7984 and Opata 85 , differed significantly in resistance to $P$. thornei

Mean transformed nematode counts for the 2 years of phenotyping are shown. Resistance level to P. thornei determined by glasshouse phenotyping trials: R, resistant; $\mathrm{S}$, susceptible. Equivalent means are shown in parentheses as number of $P$. thornei/kg soil plus roots after 16 weeks growth

\begin{tabular}{lccc}
\hline Genotype & $\begin{array}{c}\text { Resistance } \\
\text { category }\end{array}$ & $\begin{array}{c}1997 \\
\ln (\text { P. thornei } / \mathrm{kg}+3500)\end{array}$ & $\begin{array}{c}2001 \\
\ln (\text { P. thornei } / \mathrm{kg}+9038)\end{array}$ \\
\hline W-7984 & $\mathrm{R}$ & $9.90(16398)$ & $9.54(4867)$ \\
GS50a & $\mathrm{R}$ & $9.99(18356)$ & $10.47(26204)$ \\
Opata 85 & $\mathrm{~S}$ & $11.34(84329)$ & $11.85(131046)$ \\
Janz & $\mathrm{S}$ & $11.40(89618)$ & $11.72(113969)$ \\
1.s.d. $(P=0.05)$ & & 0.76 & 0.84
\end{tabular}

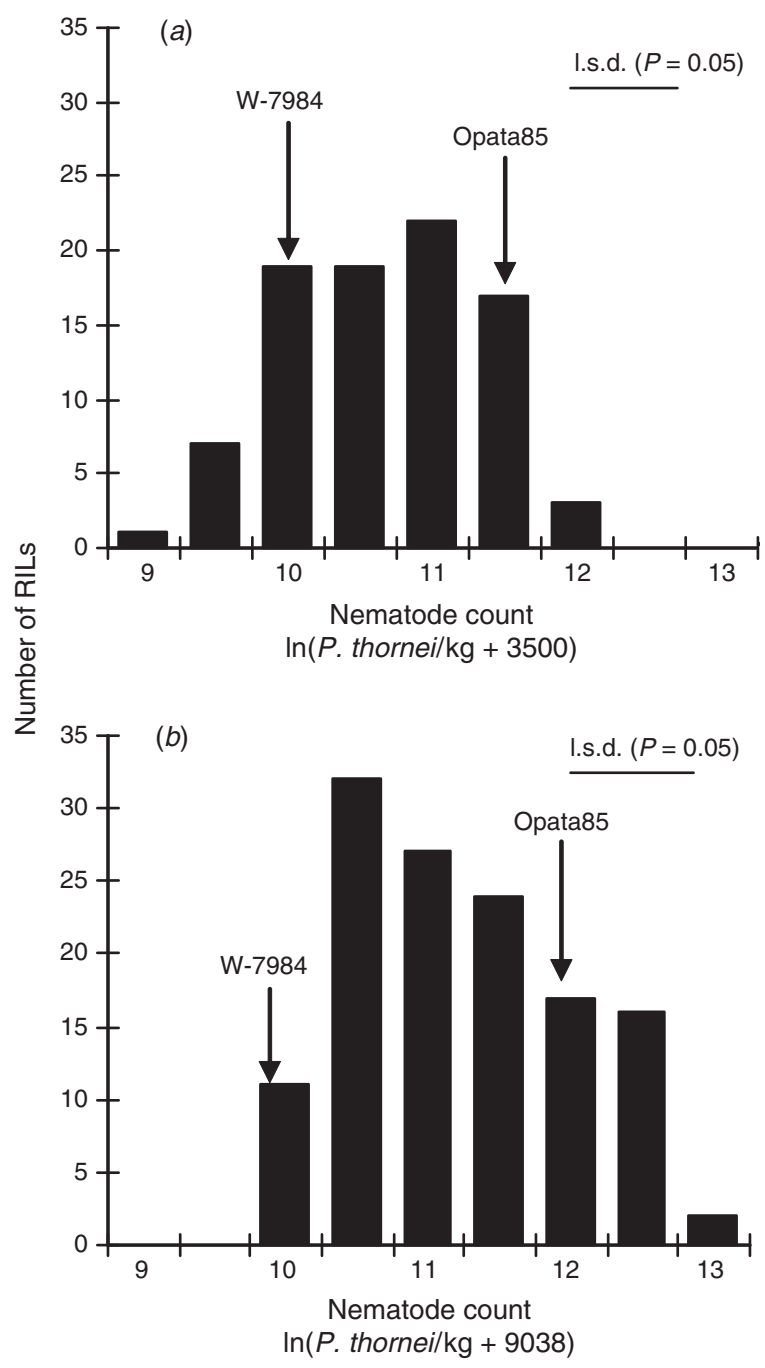

Fig. 1. Resistance to P. thornei in W-7984 $\times$ Opata 85 ITMI population is continuously distributed. (a) Frequency distribution of recombinant inbred lines (RILs) for resistance to $P$. thornei in the 1997 glasshouse experiment. The horizontal bar represents 1.s.d. $(P=0.05)$ of 0.76 . The transformed nematode count for the resistant parent, W-7984, was 9.90 and for the susceptible parent, Opata 85 , was 11.38 . The population mean was 10.44 and variance was 0.45 . (b) Frequency distribution of RILs for resistance to $P$. thornei in the 2001 glasshouse experiment. The horizontal bar represents 1.s.d. $(P=0.05)$ of 0.84 . Transformed nematode count for W-7984 was 9.54 and for Opata 85 was 11.85. The population mean was 10.95 and variance was 0.61 . than or equivalent to W-7984. Of these lines 17 RILs showed a resistance level consistently higher than or equivalent to the resistance level of W-7984 in both years of P. thornei phenotyping.

\section{QTL analysis}

QTL analysis on individual replicate data resulted in similar QTL peak locations and the results of the pooled means for each year are reported. Significant QTL associations with resistance to $P$. thornei were detected on the short arms of chromosomes 6D and 2B (Fig. 2). In both cases, the marker alleles conferring resistance in these QTL regions were inherited from the synthetic hexaploid parent, W-7984.
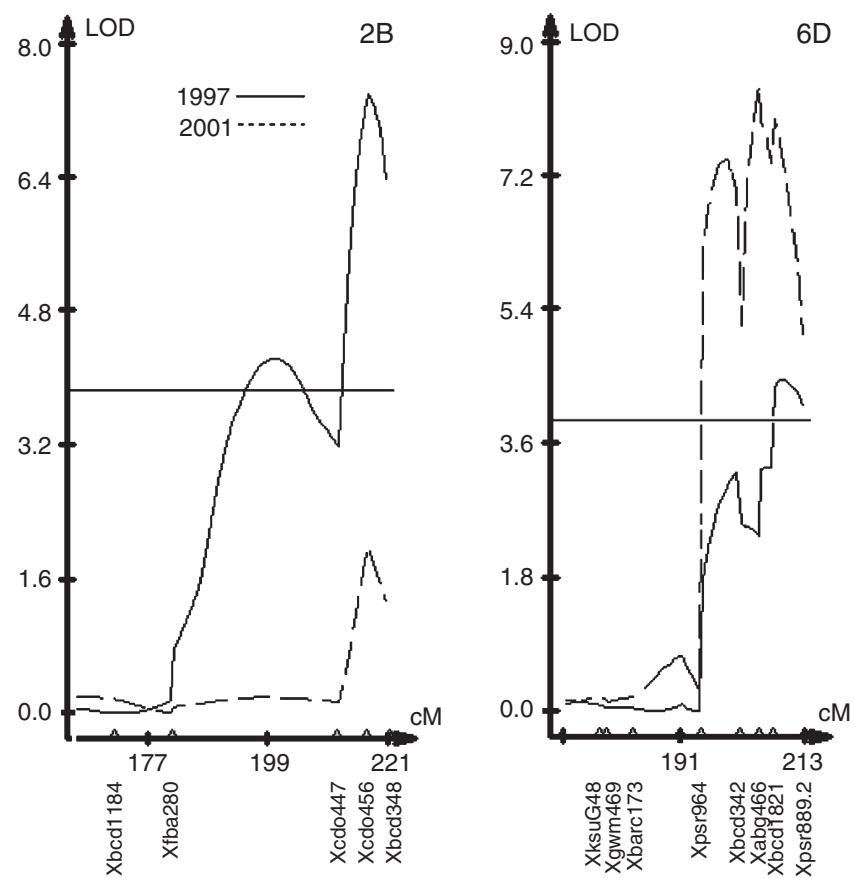

Fig. 2. Composite interval mapping (CIM) contours showing QTL for resistance to $P$. thornei in W-7984 $\times$ Opata 85 ITMI population on the short arms of chromosomes $2 \mathrm{~B}$ and $6 \mathrm{D}$. Numbers on horizontal axes represent distances in $\mathrm{cM}$ from the end of the long arms of the chromosomes. The threshold line set by permutation tests for significance $(95 \%)$ is shown at LOD 3.8 in both plots. 
The QTL on the distal end of chromosome arm 6DS explained $11 \%$ and $23 \%$ of the phenotypic variation for resistance to $P$. thornei in 1997 and 2001, respectively. OneLOD confidence intervals for the 2 years overlap. Based on the large 2001 effect, the QTL lies near RFLP marker locus Xbcd1821 (Fig. 2). The closest SSR marker locus, $X$ barc 183 , is about $6 \mathrm{cM}$ proximal but could not be reliably (LOD 2) placed.

A second QTL on chromosome 2BS explained 19\% and $5 \%$ of the phenotypic variation for resistance to $P$. thornei in 1997 and 2001, with the peak LOD value for the QTL found at RFLP marker locus $X c d o 456$ and the effect falling short of the LOD significance cut-off in 2001. A 1-LOD confidence interval localised the QTL in the 1997 data in a 3-cM region that encloses SSR marker locus Xgwm210, a marker not used in the QTL scan because it could not be reliably (LOD 2) placed on the map. The group of markers on the distal end of chromosome $2 \mathrm{BS}$, initially reported as linked to the distal end of chromosome 2AS (Nelson et al. 1995b), was later mapped to the distal end of chromosome 2BS (Röder et al. 1998; Langridge et al. 2001).

\section{Discussion}

Two QTLs for resistance to $P$. thornei in the ITMI population have been detected on chromosomes 6DS and 2BS and their locations tightly defined by flanking molecular markers. Both showed strong effects in one evaluation year and strong or suggestive effects in a second year. For both regions, the QTL resistance alleles were inherited from the synthetic hexaploid parent, W-7984. This indicates that both the B genome of the durum and the $\mathrm{D}$ genome of the Ae.tauschii parent of the synthetic hexaploid contributed to its P. thornei resistance.

Both QTLs lie in regions rich in major genes on the distal end of short chromosome arms. RFLP marker loci Xpsr964 and XksuG48 (Erayman et al. 2004) and SSR marker loci Xbarc173, Xbarc183, and Xgwm496 (Sourdille et al. 2004) have been physically mapped using deletion lines to the $10-\mathrm{Mb}$ deletion bin 6DS-0.99-1.00, which contains 2 putative R genes (Dilbirligi et al. 2004). RFLP marker locus Xbcd348 (Erayman et al. 2004) and SSR marker locus Xgwm 210 (Sourdille et al. 2004) have been physically mapped to the 39-Mb deletion bin 2BS-7-0.89-1.00, which contains 7 putative R genes (Dilbirligi et al. 2004). Genes for other agronomically important traits, including stem rust resistance $(\mathrm{Sr} 5, \mathrm{Sr} 29)$, are located on chromosome 6DS (McIntosh et al. 2003). It is interesting that the 6DS $P$. thornei resistance QTL lies very near a defence response gene locus encoding a ribosome-inactivating protein (Rip) isolated from maize ( $\mathrm{Li}$ et al. 1999). Ribosome-inactivating proteins have been reported to act on a number of plant pests and pathogens and are presumed to play an important role in defence against pathogens (Krawetz and Boston 2000).
Comparison of maps using common markers revealed that SSR marker locus Xbarc183 on chromosome 6DS was associated with resistance to $P$. thornei in this study as well as in a second mapping study in which resistance was contributed by a different synthetic hexaploid parent, CPI133872 (Zwart et al. 2005). The 6DS QTL contributed by CPI133872 explained $24 \%$ of the variation in resistance, which is similar to the value reported here. QTLs on chromosome $2 \mathrm{~B}$ for resistance to $P$. thornei have been detected in other mapping populations (Schmidt et al. 2005; Zwart et al. 2005). However, due to a lack of common markers on the $2 \mathrm{BS}$ region, comparisons between the location of the QTL identified in this study and other $P$. thornei resistance QTL studies could not be made. QRlnt.lrc-2B.1 was associated with SSR marker locus $X w m c 025 b$ and explained $7 \%$ of the variation for $P$. thornei resistance in a CPI133872 $\times$ Janz population (Zwart et al. 2005). In an AUS13124 $\times$ Janz population a QTL on chromosome 2B, flanked by SSR marker loci Xgwm319 and Xgwm494.2, explained $14 \%$ of the variation for $P$. thornei resistance (Schmidt et al. 2005).

The synthetic hexaploid wheat lines W-7984 and CPI133872, which both have QTLs for P. thornei resistance in similar locations on chromosomes 6DS and 2BS, were originally developed at the International Maize and Wheat Improvement Centre (CIMMYT), Mexico. The 6DS and 2BS QTLs in W-7984 may be allelic to QRlnt.lrc-6D.1 and QRlnt.lrc-2B.1 identified in CPI133872, although there is no direct evidence for this as the wheat lines were derived from different durum and Ae. tauschii lines. The pedigree of CPI133872 (CIMMYT Synthetic ID No. 177 and CIGM89.576 in appendix 2, Mujeeb-Kazi 1995) is durum 68.111/Rugby//Ward/3/Flamingo/4/Rabicorno (syn. CPI 133821) crossed with Ae. tauschii (CIMMYT WX 949; syn. TA2525 and AUS24199).

The consistency and size of the heritability estimates indicate that much of the phenotypic variation for resistance to $P$. thornei in the ITMI population is accounted for by genetic variation. Together with the QTL mapping results, this suggests that much of the resistance to $P$. thornei is controlled by a few loci with relatively large effects in this population. The coincidence in locations of QTLs associated with SSR marker loci Xbarc183 on chromosome 6DS, found in different mapping studies, suggests the utility of this marker for use in marker-assisted selection with material from different genetic backgrounds. It also suggests the importance of investigations for alternative sources of resistance to $P$. thornei so that resistance genes conferring partial resistance can be pyramided.

\section{Acknowledgments}

We wish to thank T. G. Clewett for technical assistance, Dr P. J. Sharp, University of Sydney, Australia, and Dr K. J. Chalmers, University of Adelaide, Australia, for 
providing seed of the ITMI population, and Dr P. S. Brennan for suggesting an investigation of $P$. thornei resistance in this population. This work was supported by the Grains Research and Development Corporation of Australia.

\section{References}

Berry DA (1987) Logarithmic transformations in ANOVA. Biometrics 43, 439-456.

Brennan JP, Murray GM (1998) 'Economic importance of wheat diseases in Australia.' (NSW Agriculture: Wagga Wagga)

Churchill GA, Doerge RW (1994) Empirical threshold values for quantitative trait mapping. Genetics 138, 963-971.

Dilbirligi M, Erayman M, Sandhu D, Sidhu D, Gill KS (2004) Identification of wheat chromosomal regions containing expressed resistance genes. Genetics 166, 461-481. doi: 10.1534/genetics. 166.1.461

Erayman M, Sandhu D, Sidhu D, Dilbirligi M, Baenziger PS, Gill KS (2004) Demarcating the gene-rich regions of the wheat genome. Nucleic Acids Research 32, 3546-3565. doi: 10.1093/nar/gkh639

Hartl DL, Freifelder D, Snyder LA (1988) Quantitative genetics. In 'Basic genetics'. (Jones and Bartlett: Boston, MA)

Krawetz JE, Boston RS (2000) Substrate specificity of a maize ribosome-inactivating protein differs across diverse taxa. European Journal of Biochemistry 267, 1966-1974. doi: 10.1046/j.14321327.2000.01200.x

Lander ES, Green P, Abrahamson J, Barlow A, Daly MJ, Lincoln SE, Newburg L (1987) MAPMAKER: an interactive computer package for constructing primary genetic linkage maps of experimental and natural populations. Genomics 1, 174-181. doi: 10.1016/08887543(87)90010-3

Langridge P, Lagudah ES, Holton TA, Appels R, Sharp P, Chalmers KJ (2001) Trends in genetic and genome analyses in wheat: a review. Australian Journal of Agricultural Research 52, 1043-1077. doi: 10.1071/AR01082

Li WL, Faris JD, Chittoor JM, Leach JE, Hulbert SH, Liu DJ, Chen PD, Gill BS (1999) Genomic mapping of defense response genes in wheat. Theoretical and Applied Genetics 98, 226-233. doi: $10.1007 / \mathrm{s} 001220051062$

Loof PAA (1991) The family Pratylenchidae Thorne, 1949. In 'Manual of agricultural nematology'. (Ed. WR Nickle) pp. 363-421. (Marcel Dekker: New York)

Marino CL, Nelson JC, Lu YH, Sorrells ME, Leroy P, Lopes CR, Hart GE (1996) Molecular genetic maps of the group 6 chromosomes of hexaploid wheat (Triticum aestivum L. em. Thell.). Genome 39, 359-366.

McIntosh RA, Yamazaki Y, Devos KM, Dubcovsky J, Rogers WJ, Appels R (2003) Catalogue of gene symbols for wheat. In 'Proceedings of the 10th International Wheat Genetics Symposium'. Vol. 4. (Eds NE Pogna, M Romanò, E Pogna, G Gatterio) pp. 1-43. (Istituto Sperimentale per la Cerealicoltura: Rome)

Mujeeb-Kazi A (1995) Interspecific crosses: hybrid production and utilisation. In 'Utilizing wild grass biodiversity in wheat improvement: 15 years of wide cross research at CIMMYT'. (Eds A Mujeeb-Kazi, GP Hettel) (CIMMYT: Mexico, DF)

Nelson JC, Sorrells ME, Van Deynze AE, Lu YH, Atkinson M, Bernard M, Leroy P, Faris JD, Anderson JA (1995a) Molecular mapping of wheat: major genes and rearrangements in homoeologous groups 4, 5, and 7. Genetics 141, 721-731.

Nelson JC, Van Deynze AE, Autrique E, Sorrells ME, Lu YH, Merlino M, Atkinson M, Leroy P (1995b) Molecular mapping of wheat. Homoeologous group 2. Genome 38, 516-524.
Nelson JC, Van Deynze AE, Autrique E, Sorrells ME, Lu YH, Negre S, Bernard M, Leroy P (1995c) Molecular mapping of wheat. Homoeologous group 3. Genome 38, 525-533.

Nicol JM, Davis KA, Eastwood R (1998) AUS4930: a new source of resistance to root-lesion nematode, Pratylenchus thornei in wheat. In '24th European Society of Nematologists International Symposium'. Dundee, Scotland, p. 81.

Payne RW, Baird DB, Cherry M, Gilmour AR, Harding SA, Kane AF, Lane PW, Murray DA, Souter DM, Thompson R, Todd AD, Tunnicliffe-Wilson G, Webster R, Welham SJ (2002) 'GenStat Release 6.1 Reference Manual.' (VSN International: Oxford)

Proctor JR, Marks CF (1974) The determination of normalizing transformations for nematode count data from soil samples and of efficient sampling schemes. Nematologica 20, 395-406.

Röder MS, Korzun V, Wendehake K, Plaschke J, Tixier MH, Leroy P, Ganal MW (1998) A microsatellite map of wheat. Genetics 149, 2007-2023.

Schmidt AL, McIntyre CL, Thompson JP, Liu CJ (2005) Quantitative trait loci for root lesion nematode (Pratylenchus thornei) resistance in Middle-Eastern landraces and their potential for introgression into Australian bread wheat. Australian Journal of Agricultural Research 56, 1059-1068.

Seymour NP, Thompson JP (2001) New sources of resistance to rootlesion nematodes (Pratylenchus thornei) in wheats from the Middle East. In 'Proceedings of the 10th Assembly of the Wheat Breeding Society of Australia'. (Eds R Eastwood, G Hollamby, T Rathjen, $\mathrm{N}$ Gororo) pp. 56-59. (Wheat Breeding Society of Australia: Adelaide, S. Aust.)

Shah MS, Hassan A (2005) Distribution of genes and recombination on wheat homoeologous group 6 chromosomes: a synthesis of available information. Molecular Breeding 15, 45-53. doi: 10.1007/s11032004-1844-4

Singh RP, Nelson JC, Sorrells ME (2000) Mapping Yr28 and other genes for resistance to stripe rust in wheat. Crop Science 40, 1148-1155.

Somers DJ, Isaac P, Edwards K (2004) A high-density microsatellite consensus map for bread wheat. Theoretical and Applied Genetics 109, 1105-1114. doi: 10.1007/s00122-004-1740-7

Song QJ, Shi JR, Singh S, Fickus EW, Costa JM, Lewis J, Gill BS, Ward R, Cregan PB (2005) Development and mapping of microsatellite (SSR) markers in wheat. Theoretical and Applied Genetics 110, 550-560. doi: 10.1007/s00122-004-1871-x

Sourdille P, Singh S, Cadalen T, Brown-Guedira GL, Gay G, Qi L, Gill BS, Dufour P, Murigneux A, Bernard M (2004) Microsatellite-based deletion bin system for the establishment of genetic-physical map relationships in wheat (Triticum aestivum L.). Functional \& Integrative Genomics 4, 12-25. doi: 10.1007/ s10142-004-0106-1

Thompson JP, Brennan PS, Clewett TG, Sheedy JG, Seymour NP (1999) Progress in breeding wheat for tolerance and resistance to root-lesion nematode (Pratylenchus thornei). Australasian Plant Pathology 28, 45-52. doi: 10.1071/AP99006

Thompson JP, Haak MI (1997) Resistance to root-lesion nematode (Pratylenchus thornei) in Aegilops tauschii Coss., the D-genome donor to wheat. Australian Journal of Agricultural Research 48, 553-559. doi: 10.1071/A96167

Thompson JP, Mackenzie J, McCulloch J, Clewett TG (1982) Integrated control of root-lesion nematode. Queensland Wheat Research Institute Biennial Report for 1980-82, pp. 31-32. QDPI, Toowoomba.

Van Deynze AE, Dubcovsky J, Gill KS, Nelson JC, Sorrels ME, Dvorák J, Gill BS, Lagudah ES, McCouch SR, Appels R (1995) Molecular-genetic maps for group 1 chromosomes of Triticeae species and their relation to chromosomes in rice and oat. Genome 38, 45-59. 
Vanstone VA, Rathjen AJ, Ware AH, Wheeler RD (1998) Relationship between root-lesion nematodes (Pratylenchus neglectus and $P$. thornei) and performance of wheat varieties. Australian Journal of Experimental Agriculture 38, 181-188. doi: 10.1071/ EA97109

Wang S, Basten CJ, Zeng Z-B (2005) Windows QTL Cartographer 2.5. Department of Statistics, North Carolina State University, Raleigh, NC. Available online at: statgen.ncsu.edu/qtlcart/ WQTLCart.htm)

Zwart RS, Thompson JP, Godwin ID (2004a) Genetic analysis of resistance to root-lesion nematode (Pratylenchus thornei Sher and Allen) in wheat. Plant Breeding 123, 209-212. doi: 10.1111/j.14390523.2004.00986.x
Zwart RS, Thompson JP, Williamson PM, Seymour NP (2004b) Elite sources of resistance in wheat to root-lesion nematode (Pratylenchus thornei and Pratylenchus neglectus) and yellow spot (Pyrenophora tritici-repentis). In 'Proceedings of the 3rd Australasian Soilborne Diseases Symposium'. (Eds KM Ophel Keller, BH Hall) p. 220. (South Australian Research and Development Institute: Adelaide, S. Aust.)

Zwart RS, Thompson JP, Godwin ID (2005) Identification of quantitative trait loci for resistance to two species of root-lesion nematode (Pratylenchus thornei and P. neglectus) in wheat. Australian Journal of Agricultural Research 56, 345-352. doi: 10.1071/AR04223

Manuscript received 18 May 2005, accepted 7 December 2005 